\title{
SOME OBSERVATIONS ON THIOURACIL NEUTROPENIA, WITH SPECIAL REFERENCE TO THE STERNAL MARROW
}

\author{
BY \\ E. K. BLACKBURN \\ Department of Pathology, The Royal Infirmary, Sheffield
}

(RECEIVED FOR PUBLICATION, JULY 7, 1948)

It is generally agreed that leucopenia, with its clinical sequelae, is the most important and occasionally serious toxic manifestation in treatment with the widely used th ourea group of drugs (Lesses and Gargill, 1945 ; Morgans, 1947 ; Dunlop, 1947 ; etc.). The average incidence of agranulocytosis in patients so treated appears to be approximately 2 per cent (Moore, 1946 ; Van Winkle and others, 1946), and 28 per cent of sixtyone cases of this condition reviewed by Morton (1947) died. In view of these and similar findings, it is considered that the results of an investigation of the sternal marrow in cases of thiouracil neutropenia may be of some interest.

A series of six patients who developed neutropenia during the year 1947, while under treatment with methyl (4) or propyl (2) thiouracil, will be considered. The criterion of neutropenia was taken as a peripheral absolute granulocyte count of less than 1,500 per c.mm. of blood (Osgood and others, 1939). A differential count of 500 nucleated marrow cells was made in each case, except in No. 1, in which 1,000 such cells were counted. In none was there evidence of a primary blood dyscrasia which might be associated with an absolute neutropenia. Brief clinical details of these patients are given in the appendix to this report (p. 299).

\section{The Six Cases}

Case 1. - The sternal marrow was first examined on April 3, 1947, when only 64 granulocytes per c.mm. were found in the peripheral blood. Stained films showed normal numbers of earlier, with very scanty later, myeloid forms (see Tabie, Case 1a). There appeared to be a rise in lymphocytes and plasma cells, and a normoblastic reaction (she had hypochromic anaemia ; $\mathrm{Hb}, 70$ per cent Hellige -100 per cent $=14$ g. per $100 \mathrm{ml}$. blood-on April 3, 1947).
Morphological abnormalities were seen in 55 cells of the myeloid series. Thus some myeloblasts showed, in varying combination, an irregularly shaped nucleus, and scanty, irregularly staining, vacuolated cytoplasm, with irregular outer margin and pseudopodium-like formation (Plate I, Figs. 1 and 2). Promyelocytes with an abnormally large, often irregular nucleus, and cytoplasm showing the features mentioned above, along with coarse granulation (Figs. 3-7), could be seen. The large numbers of ce'ls reported as bare nuclei throughout the series showed, in the main, the general morphology of myeloblastic or premyelocytic nuclei (Fig. 8). Some were degenerated mature granulocytes (Fig. 9).

The cytoplasm of the neutrophil myelocytes showed the abnormal features observed in the premyelocytes, except that the granules were often ill-defined, and seemed to fuse with the cytoplasm (Fig. 10). Irregularity of nuclear outline could be seen in one cell.

The single metamyelocyte encountered also showed irregularly staining cytoplasm with ill-defined granulation, while the neutrophil polymorph exhibited similar granulation, along with an abnormally pale, vacuolated cytoplasm and a pyknotic nuc'eus.

The sternum was punctured for the second time on April 5, 1947. No granulocytes were then seen in the peripheral blood smears. Examination of the marrow (Table, $1 b$ ) showed even more marked myeloid suppression than on April 3, the promyelocyte level being especially affected. In general, the myeloid morphology resembled that seen in the first marrow specimen. Additional features worthy of note amongst the 56 abnormal cells were: one myeloblast showed a partly segmented nucleus, the lobes being joined by a relatively narrow chromatin band (Fig. 11); and the promyelocytes showed the ill-defined granules previously mentioned (Figs. 8, 12, and 13). Some neutrophil myelocytes were abnormally large, and granules were often absent from the cytoplasm, or were of very coarse type (Figs. 14 and 15). A few metamyelocytes showed scanty irregularly staining cytoplasm, with irregular 
TABLE

MYELOGRAMS IN THIOURACIL NEUTROPENIA

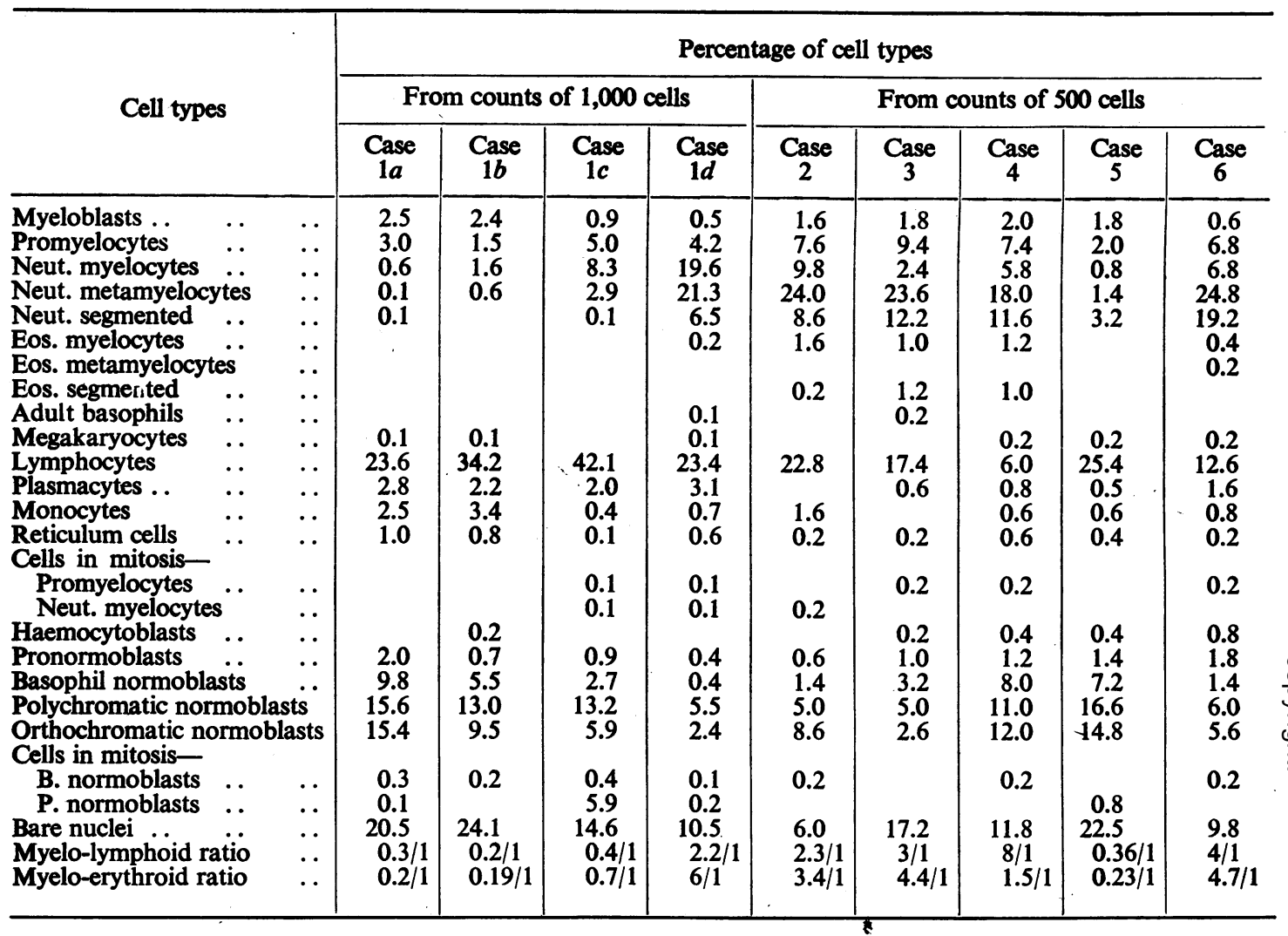

outline, vacuolation, and ill-defined or absent granules (Fig. 16).

A further puncture was performed on April 7, 1947, at a time when granulocytes were beginning to reappear in the peripheral blood smears (64 per c.mm.). The sternal marrow (Table, 1c) showed evidence of myeloid regeneration, and only one abnormal myeloblast with vacuolated cytoplasm could be seen. Many of the promyelocytes showed abnormal features as described above. Some of the neutrophil myelocytes were abnormally large ; the nucleus of some exhibited nucleoli, and the cytoplasm of others, was completely disrupted (Fig. 17). A fresh feature noted in the cytoplasm of metamyelocytes was the coarse granulation; that of the single polymorph was abnormally pale, with irregular outline and devoid of granules (Fig. 18) (120 abnormal myeloid cells were seen).

The final puncture, performed on April 10, 1947, was made when the peripheral granulocyte count was rising rapidly. The smears showed marked evidence of myeloid regeneration (Table, 1d). All the myeloblasts appeared normal, and only 39 of the remaining myeloid cells showed any of the abnormal morphological features described above.
Case 2.-Sternal puncture was performed on Oct. 30, 1947, peripheral blood smears showing 1,160 granulocytes per c.mm. There appeared to be a "myeloid maturation defect" (Table, 2). The myeloblast morphology was normal, but 25 of the more differentiated myeloid forms showed abnormalities of structure of the types described in Case 1. Additional features worthy of note were 2 metamyelocytes with abnormally large nuclei (Fig. 19), and one eosinophil myelocyte with vacuolated cytoplasm.

Case 3.-On March 26, 1947, 1,200 granulocytes per c.mm. were seen in peripheral blood smears. The marrow (Table, 3) showed a relatively slight apparent myeloid "maturation defect," while 27 myeloid cells exhibited abnormalities of the types noted in the previous cases (Fig. 20).

Case 4. - The peripheral granulocyte level standing at 854 per c.mm. sternal marrow smears obtained on May 20, 1947, showed an apparent "maturation defect" in the myeloid cells (Table, 4). The normoblastic reaction was expected in view of chronic haematuria (on admission she had 50 per cent $\mathrm{Hb}$, Hellige). Worthy of note was the disrupted cyto- 
plasm of two neutrophil polymorphs and two eosinophil polymorphs (Fig. 9); otherwise, the 20 abnormal myeloid cells showed no features not already seen in the other cases.

Case 5.-On June 1, 1947, when the sternal marrow was examined, there were 504 granulocytes per c.mm. in the peripheral blood. Again the Table (5) shows a myeloid "maturation defect," and 27 abnormal myeloid cells showed changes described above.

Case 6.- Sternal marrow puncture was performed on Dec. 1, 1947, when 1,250 granulocytes per c.mm. were seen in the peripheral b.ood. Marrow smears (Table, 6) showed 10 abnormal immature myeloid cells, 1 myeloblast, 2 neutrophil myelocytes, and 7 premyelocytes with neutrophil myelocytic nuclei. Otherwise there was no new feature.

Sternal marrow examinations were carried out on five thyrotoxic patients in whom no neutropenia occurred during thiouracil therapy. In these, neither the morphological abnormalities, nor the marked myeloid depression described in the six neutropenic cases, were observed.

\section{Discussion}

The six cases showed varying grades of neutropenia up to complete agranulocytosis in Case 1. The sternal marrow appeared to contain an excess of lymphocytes in Cases 1,2, and 5, and of plasmacytes in Case 1, these findings being common in cases of neutropenia and agranulocytosis (Darling and others, 1936). The lymphocyte morphology was normal throughout, no cells of the type described by Downey and Stasney (1936) being evident. There appeared to be no significant increase in reticulum cells and haematogones (haemocytoblasts) such as McGavack and others (1944) found in a case of thiouracil neutropenia. The erythropoietic tissue showed no constant variation from normal, as one would expect (Wintrobe, 1946a). In no case was there a megakaryocytic increase, found by Gessler (1946) in two of his series of nine patients. The latter had been treated with thiouracil, and two had developed neutropenia.

The most striking changes were found in the myeloid series; they were constantly depressed (see Table), and displayed morphological alterations as described above. Gessler (1946) and Limarzi and Ricewasser (1946) have reported a few of these, while some of the other abnormalities have been described previously in cases of agranulocytosis not associated with thiouracil (Rotter, 1925; Jaffé, 1933 ; etc.). There were obvious discrepancies in the maturation of the nucleus and cytoplasm throughout the series (Plate I, Figs. 1, 8, 11, 13, 17, and 19).

The mechanism of the depression of the bone marrow, and of the leucopenia, has by no means been fully elucidated. Neutropenia appears to depend on the development of hypersensitivity of the white cells to the drug, and other symptoms suggestive of allergy appear from time to time during treatment-for example, skin rashes and drug fevers (Witts, 1936 ; Plum, 1937 ; Hadler, 1940 ; Lesses and Gargill, 1945; Fishberg and Vorzimer, 1945 ; etc.). Our case of agranulocytosis developed erythema, but none of the cases showed eosinophilia at any stage. Williams and Clute (1944) showed that patients may recover from neutropenia with continued administration of the drug, and desensitization to thiouracil has been noted by several authors (Sprunt, 1944 ; Rose and McConnell, 1944). However, Williams and others (1944) have shown that human bone marrow is one of the tissues most highly saturated with the drug. They also found that the concentration of thiouracil in the leucocytes was greater than in the erythrocytes. Palmer (1944) supports these findings, and Warren (1945) showed that thiouracil produced a small but significant inhibition of respiration of rabbit bone marrow cells, more especially of the immature myeloid cells. Thus a direct toxic effect of the drug may play a part. It is felt that the morphological abnormalities described above, and affecting even the earliest myeloid cells, and the discrepancies in maturation between the nucleus and cytoplasm strongly support this view. Noteworthy, too, is the chemica ly close relationship of the thiourea drugs to barbitone or diethylbarbituric acid, which latter occasionally gives rise to agranulocytosis (Watkins, 1933). That the neutropenia does not arise from thyrotoxicosis per se has been adequately shown (Lesses and Gargill, 1945), and there is evidence that anoxia does not play an important part (Rosin and Rachmilewitz, 1948).

Whether depressed function of the marrow is due to allergy or to a direct toxic effect and overdosage, or both, actual production of the neutropenia would appear to be explicable by either one or other of the following concepts:

(1) The much favoured "maturation arrest" (Fitz-Hugh and Krumbhaar, 1932; Fitz-Hugh and Comroe, 1933), in which the effect is exerted on the precursors of granulocytes, interfering with their maturation. Thus Rubinstein (1944) performed serial marrow examinations in a case of severe thiouracil neutropenia and came to the conclusion that agranulocytosis was caused by arrest of maturation associated with hypoplasia.

(2) Plum's (1937) evidence favours the view that the bone marrow in agranulocytosis goes through a number of stages. The first is a reduc- 
tion of granulocyte precursors, soon followed by a loss of mature and then immature granulocytes. Recovery is heralded by the reappearance of granulocyte precursors, the picture then being one of so-called " maturation arrest." Later, the mature granulocytes return. (It is of interest to note that Jaffé, 1933, described three cases of idiopathic agranulocytosis, and one following anti-luetic treatment. The femoral marrow at autopsy was hyperplastic, the granulopoietic tissue taking an active part. He thought, therefore, that in some instances the agranulocytic catastrophe was preceded by proliferation of young myelocytes.) The work of Braun (1944), of Dameshek (1944), and of Sikkema and others (1946) supports this second view.

Our'cases would also seem to favour the Plum concept, both from the evidence of a direct toxic effect already mentioned and from that afforded by the differential marrow counts in the Table. There is evidence of proliferation of earlier myelocytes in most cases, and in Case 1 this preceded the development of the more mature granulocytes. Also in favour are the large number of "bare nuclei " showing the general morphology of myeloblastic or premyelocytic nuclei. We must remember, however, that destruction of some of the granulocytes may occur in the circulating blood (Lawrence, 1941).

Fisher (1947) pointed out that neutrophil leucopenia occurred in his series of cryptogenic acquired haemolytic anaemias only in those cases with liver dysfunction. In retrospect, he noted that neutropenia was the only early and constant herald of liver dysfunction. It is interesting to speculate about the hepatic role in thiouracil neutropenia. The liver is affected in hyperthyroidism. There is often passive congestion, and degenerative changes are common. Fatty change, acute necrosis, both focal and central, and subacute toxic atrophy with the development of cirrhosis occur frequently. Liver function tests often show marked impairment (Weller, 1930; Beaver and Pemberton, 1933 ; Boyd, 1943). In addition, thiouracil therapy may be associated with jaundice and hepatic enlargement (Kahn and Stock, 1944 ; Paschkis, 1944 ; Sloan and Shorr, 1944 ; Lesses and Gargill, 1945 ; Linnell and others, 1946 ; Livingston and Livingston, 1947). Case 5 had hepatomegaly, but all the generally accepted liver function tests were normal, except the galactose tolerance test, which gave a value of $4.5 \mathrm{~g}$. excreted in five hours after $40 \mathrm{~g}$. had been taken by mouth. Case 3 showed a similar result, and a serum alkaline phosphatase of $19 \mathrm{~K}$-A units. Otherwise, the usual liver function tests were normal throughout our series. This latter does not support the view that liver function has much to do with thiouracil neutropenia.

Peripheral blood films in the six cases showed varying grades of degeneration of some granulocytes. Some had a pyknotic nucleus, or a pale nucleus with no cytoplasm but sùrrounded by granules. Vacuolation of the cytoplasm, abnormal bluish staining, and coarse and fine poorly staining granules were seen. In no case was a leucocytosis detected on recovery (cf. Reznikoff, 1938 ; Lesses and Gargiil, 1945 ; Kneedler, 1946 ; etc.).

Bacteriological cultures of the marrow under aerobic (blood agar, glucose broth) and anaerobic (blood agar and Robertson's meat medium) conditions were carried out in Cases 1, 3, 4, and 5. After fourteen days' incubation they remained sterile. In each case the marrow sample was taken before the commencement of penicillin therapy. These findings support the view that the neutropenia is not primarily due to an infection (Wintrobe, 1946b).

Our cases (see appendix) confirm the fact that no general rules will guarantee freedom from serious haematological reactions. Neutropenia was seen at very different dosage levels, and after short and prolonged periods of administration. Clinical symptoms are not reliable as an indication of the blood picture; thus Case 5 has continued over the past year free from symptoms, with a granulocyte count remaining at about the 1,000 per c.mm. level.

The sternal marrow pictures of one patient who developed agranulocytosis and of five who developed neutropenia while under treatment with thiouracil derivatives are described, with particular reference to numerical and morphological changes in the myeloid series, which was constantly depressed.

The mechanism of this depression is discussed, and evidence in favour of a direct toxic effect of the drug is given. The morphological abnormalities described, affecting even the earliest myeloid cells, and the discrepancies in maturation between the nucleus and cytoplasm strongly support this view.

The mode of production of thiouracil neutropenias is better explained by the Plum (1937) concept than by that of "maturation arrest."

The liver function tests performed on these cases do not uphold the view that liver function has much connexion with thiouracil neutropenias.

Bacteriological cultures of the sternal marrow were sterile in four cases examined by suitable methods. This negatives infection as a primary cause of the neutropenias. 
It was confirmed that no general rules will guarantee freedom from serious haematological reactions, and clinical symptoms are not reliable as an indication of the blood picture.

I wish to thank Prof. H. N. Green and Dr. L. C. D. Hermitte for their kind encouragement and advice ; Prof. E. J. Wayne and Dr. H. P. Brody for their willing assistance, and for access to their cases; and Drs. W. D. Wallace, R. H. Canter, and J. F. Goodwin, Mrs. G. R. Maclachlan, and the technical staff for help with various aspects of the work.

\section{REFERENCES}

Beaver, D. C., and Pemberton, J. de J. (1933). Ann. intern. Med., 7, 687.

Boyd, W. (1943). “A Textbook of Pathology." London. P. 738.

Braun, K. (1944). Acta med. Orient, 3, 120. Abstracted in Yr. Bk. Gen. Med., 1945, p. 379.

Dameshek, W. (1944). Oxford Medicine, 2, 848 (15)

Darling, R. C., Parker, F., Jr., and Jackson, H., Jr. (1936). Amer. J. Path., 12, 1 .

Downey, H., and Stasney, J. (1936). Folia Haemat. Lpz., 54, 417.

Dunlop, D. M. (1947). Lancet, 2, 517.

Fishberg, E. H., and Vorzimer, J. J. (1945). Proc. Soc. exp. Biol., N.Y., 60, 181 .

Fisher, J. A. (1947). Quart. J. Med., n.s., 16, 245.

Fitz-Hugh, T., and Comroe, B. I. (1933). Amer. J. med. Sci., 185, 552

Fitz-Hugh, T., and Krumbhaar, E. B. (1932). Amer. J. med.Sci., 183, 104.

Gessler, C. J. (1746). Blood, 1, 407

Hadler, A. J. (1940). New Engl. J. Med., 222, 755

Jaffé, R. H. (1933). Arch. Path., 16, 611.

Kahn, J., and Stock, R. P. (1944). J. Amer. med. Ass., 126, 358

Kneedler, W. H. (1946). Brit. med. J., 1, 876.

Lawrence, J. S. (1941). J. Amer. med. Ass., 116, 478.

Lesses, M. F., and Gargill, S. L. (1945). New Engl. J. Med., $233,803$.

Limarzi, L. R., and Ricewasser, H. (1946). Amer. J. clin. Path., 16, 306.

Linnell, J. W., Keynes, G., and Piercy, J. E. (1946). Brit. med. J., 11, 449.

Livingston, H. J., and Livingston, S. F. (1947). J. Amer. med. Ass., $135,422$.

McGavack, T. H., Gerl, A. J., Vogel, M., and Schwimmer, D. (1944). J. clin. Endocrinol., 4, 249.

Moore, F. D. (1946). J. Amer. med. Ass., 130, 315.

Morton, J. H. (1947). Amer. J. Med., 2, 53.

Morgans, M. E. (1947). Lancet, 1, 519.

Osgood, E. E., Brownlee, I. E., Osgood, M. W., Ellis, D. M., and Cohen, W. (1939). Arch. intern. Med., 64, 105.

Palmer, V.(1944). Bull. School Med. Univ. Maryland, 28, 125

Paschkis, K. E. (1944). Med. Clin. N. Amer., 28, 1362.

Paschkis, K. E. (1944). Med. Clin. N. Amer., 28, 1362. Agranulocytosis." London.

Reznikoff, P. (1938). Amer. J. med. Sci., 195, 627.

Rose, E., and McConnell, J. (1944). Amer. J. med. Sci., $208,561$.

Rosin, A., and Rachmilewitz, M. (1948). Blood, 3, 165.

Rotter, W. (1925). Virchows Arch. path. anat., 258, 17.

Rubinstein. M. A. (1944). Amer. J clin. Path. 14, 540.

Sikkema, S. H., Thewlis, E. W., and Meyer, O. O. (1946). Blood, 1, 411.

Sloan, M. H., and Shorr, E. (1944). Science, 99, 305.

Sprunt, T. P. (1944). J.S. C. med. Ass., 40, 91.

Van Winkle, W. Jr., Hardy, S. M., Hazel, G. R., Hines, D. C. Newcomer, H. S., Sharp, E. A., and Sisk, W. N. (1946). J. Amer. med. Ass., 130, 343.

Watkins, C. H. (1933). Proc. Mayo Clin., 8, 713.

Watkins, C. H. (1933). Proc. Mayo Clin.,

Warren, C. O. (1945). Science, 102, 175.
Weller, C. V. (1930). Trans. Ass. Amer. Phys., 45, 71.

Williams, R. H., and Clute, H. M. (1944). New Engl. J. Med., 230, 657.

Williams, R. H., Kay, G. A., and Jandorf, B. J. (1944). J. clin. Invest, $23,613$.

Wintrobe, M. M. (1946a). “Clinical Hematology.” London. P. 795. Wintrobe, M. M. (1946b). "Clinical Hematology." London. P. 790.

Witts, L. J. (1936). Brit. med. J., 2, 211.

\section{Appendix}

Case 1.-A married woman aged 62 years was admitted to hospital with typical thyrotoxicosis and congestive heart failure. Methyl thiouracil, $0.2 \mathrm{~g}$. three times a day, was begun on March 12, 1947.
The granulocytes fell from 2,120 on March 5 to 1,122 per c.mm. on March 12, after which a satisfactory level was maintained until March 31, when a value of 1,188 per c.mm. was found. On March 24 thiouracil therapy had been stopped for twenty-four hours in view of a transient mild sore throat. The granulocytes fell to 64 per c.mm. (total leucocytes 3,200 per c.mm.) by April 3; the drug was again stopped, and the first sternal puncture performed. Treatment with penicillin, intravenous pyridoxine, and intramuscular pentnucleotide was begun, her only fresh symptom being a slight sore throat.

A few hours after the first sternal puncture on April 3 she complained of malaise, headache, pains in her back and limbs, and a sore throat. At 6 p.m. she had a rigor, her temperature rising to $101^{\circ} \mathrm{F}$. She appeared acutely ill, with flushed facies and coated tongue. Her fauces were injected, but no exudate was evident. Slightly enlarged, tender, tonsillar lymph nodes were palpated. There was no splenic or hepatic enlargement, and no bone tenderness, icterus, or skin rash.

The following day the temperature remained intermittent, and the peripheral granulocyte level stood at 60 per c.mm., with a total leucocyte count of 3,000 per c.mm. At 10.40 p.m. she experienced a rigor, this being thrice repeated on April 5, on which day she developed generalized erythema, and had a leucocyte count of 2,800 per c.mm., no neutrophil polymorphs being evident in peripheral or marrow films.

The complete neutropenia was maintained on April 6, and she had a rigor at 10 p.m., which was repeated the next day at 3 p.m., when her peripheral blood contained 64 granulocytes per c.mm. Another sternal marrow examination was made on April 7.

Marked c'inical improvement took place on April 8, this being reflected in her peripheral blood, which showed 704 granulocytes (64 neutrophil myelocytes, 96 metamyelocytes, and 544 polymorphs), out of a total of 3,200 leucocytes per c.mm. The following day no neutrophil myelocytes were seen, and the granulocyte level rose to 924 per c.mm. The final marrow smears were examined on April 10, 1947.

Thereafter, the patient's leucocyte counts were satisfactory, and methyl thiouracil $0.2 \mathrm{~g}$. twice a day was recommenced on April 29. Agranulocytosis which, apart from a moderate rise of temperature, was symptomless developed suddenly on May 19 . The drug was stopped and she recovered on suitable treatment.

Eight months later, in view of increasing toxicity, and the previous reactions to methyl thiouracil, thyroidectomy was performed after suitable preoperative treatment. The patient died a few hours later in a thyroid crisis.

Case 2.-In 1941 a married woman aged 45 years had a subtotal thyroidectomy for typical thyrotoxicosis. In view of recurrent toxic symptoms, methyl thiouracil $50 \mathrm{mg}$. per day was begun on Aug. 8, 1946. The dose was reduced to $25 \mathrm{mg}$. daily on Oct. 31 , being raised again to $50 \mathrm{mg}$. on March 27, 1947 . Her granulocyte count was satisfactory until Oct. 24,1947 , when a leucopenia (2,600 per c.mm.) and neutropenia (936 per c.mm.) were found. The granulocyte level varied between 936 and 1,160 per c.mm. Over the next few symptomless days, thiouracil therapy being stopped and penicillin and pyridoxine exhibited on Oct. 26, 1947. Sternal puncture was performed on Oct. 30, 1947. 
Case 3.-A married woman aged 38 years was admitted to hospital with auricular fibri'lation and congestive heart failure due to primary thyrotoxicosis. Propyl thiouracil $50 \mathrm{mg}$. three times a day was given for fourteen days, $25 \mathrm{mg}$. three times a day for the next five days, and then $25 \mathrm{mg}$. twice daily for seventeen days, after which (March 20, 1947) $25 \mathrm{mg}$. daily sufficed. Her total leucocyte count varied between 3,000 and 3,600 per c.mm. from March 17 until March 26, when her sternal marrow was examined. Previous counts had been normal, and she never had symptoms attributable to neutropenia.

Case 4.-A married woman aged 43 years came into hospital on April 28, 1947, suffering from thyrotoxicosis and left pyonephrosis. Her leucocyte count was 2,400 per c.mm. with 1,584 granulocytes per c.mm. Propyl thiouracil, $50 \mathrm{mg}$. three times a day, was given, and she developed more marked leucopenia, which was symptomless and persisted for four days before her sternal marrow was examined on May 20 . On this date the peripheral blood showed 1,400 leucocytes and 854 granulocytes per c.mm.
Case 5.-A man aged 53 years, a case of primary thyrotoxicosis, was given methyl thiouracil $200 \mathrm{mg}$. per day for one month, and then $100 \mathrm{mg}$. daily for three and a half months, followed by $25 \mathrm{mg}$. daily for one year. He then developed leucopenia (3,800 per c.mm.) due to neutropenia (418 granulocytes per c.mm.) associated with palpable enlargement of liver and spleen on May 31, 1947. He had no pyrexia, sore throat, skin rash, adenitis, icterus, bone tenderness, or anaemia, the neutropenia being symptomless.

Case 6.- A married woman aged 49 years had had a thyroidectomy four years previously for toxic goitre. She relapsed, and there was a concomitant $B$. coli pyelonephritis. On admission on Nov. 28, 1947, she had hypochromic normocytic anaemia ( $\mathrm{Hb}, 67$ per cent Hellige), and leucopenia (2,000 per c.mm.) and neutropenia (1,220 granulocytes per c.mm.). The following day methyl thiouracil, $200 \mathrm{mg}$. twice a day, was begun, and her marrow was examined on Dec. 1, there having been no symptoms attributable to the neutropenia.

Legends For Plate I

(All the photomicrographs are Leishman-stained, and the magnification is $\times 1,000$ )

FIG. 1.-Myeloblast showing an irregularly shaped nucleus and irregularly staining cytoplasm with interruptions in the continuity of its outer margin.

FIG. 2-Degenerating myeloblast showing scanty, irregularly staining cytoplasm, with irregular outer margin, and pseudopodium-like formation.

FIg. 3.-Large promyelocyte with a few coarse cytoplasmic granules.

Fig. 4.-Large promyelocyte showing a cytoplasmic vacuole, and irregularity of cytoplasmic staining and outline.

FIG. 5.-Promyelocyte showing irregularly staining cytoplasm, which contains coarse granules and a vacuole.

FIG, 6--Promyelocyte showing irregularly staining cytoplasm and coarse granules.

FIG 7-Promyelocyte showing irregularly staining cytoplasm with irregular outer margin and pseudopodium-like formation. Some coarse cytoplasmic granules are seen.

FIG. 8.-Nucleus only and promyelocyte, showing morphological similarities. The promyelocyte also shows an irregularly shaped nucleus, and ill-defined granules, which seem to fuse with the cytoplasm.

FIG 9-Degenerate polymorphonuclear cell showing a stage in development of "nucleus only."
Fig. 10.- N. myelocyte showing ill-de fined granules apparently fusing with the cytoplasm.

Fig. 11.-Myeloblast showing partially segmented nucleus.

FIG. 12.-Promyelocyte with ill-defined granules apparently fusing with the cytoplasm.

FIG. 13.-Promyelocyte with irregularly shaped nucleus and granules as in Fig. 12.

FIG. 14.- $N$. myelocyte showing vacuolated cytoplasm with absent granules.

FIG. 15.-Large $N$. myelocyte with coarse cytoplasmic granules.

FIG. 16.-Metamyelocyte with scanty irregularly staining vacuolated cytoplasm and ill-defined granules.

FIG. 17. $-N$. myelocyte. The nucleus contains nucleoli. The irregularly staining cytoplasm has an uneven outer margin and contains coarse granules.

FIG. 18, - $N$. polymorph with abnormally pale cytoplasm, which has an irregular outline and is devoid of granules.

FIG. 19.-Metamyelocyte with abnormally large nucleus and ill-defined cytoplasmic granules.

Frg. 20.-Eosinophil myelocyte with disrupted cytoplasm. 


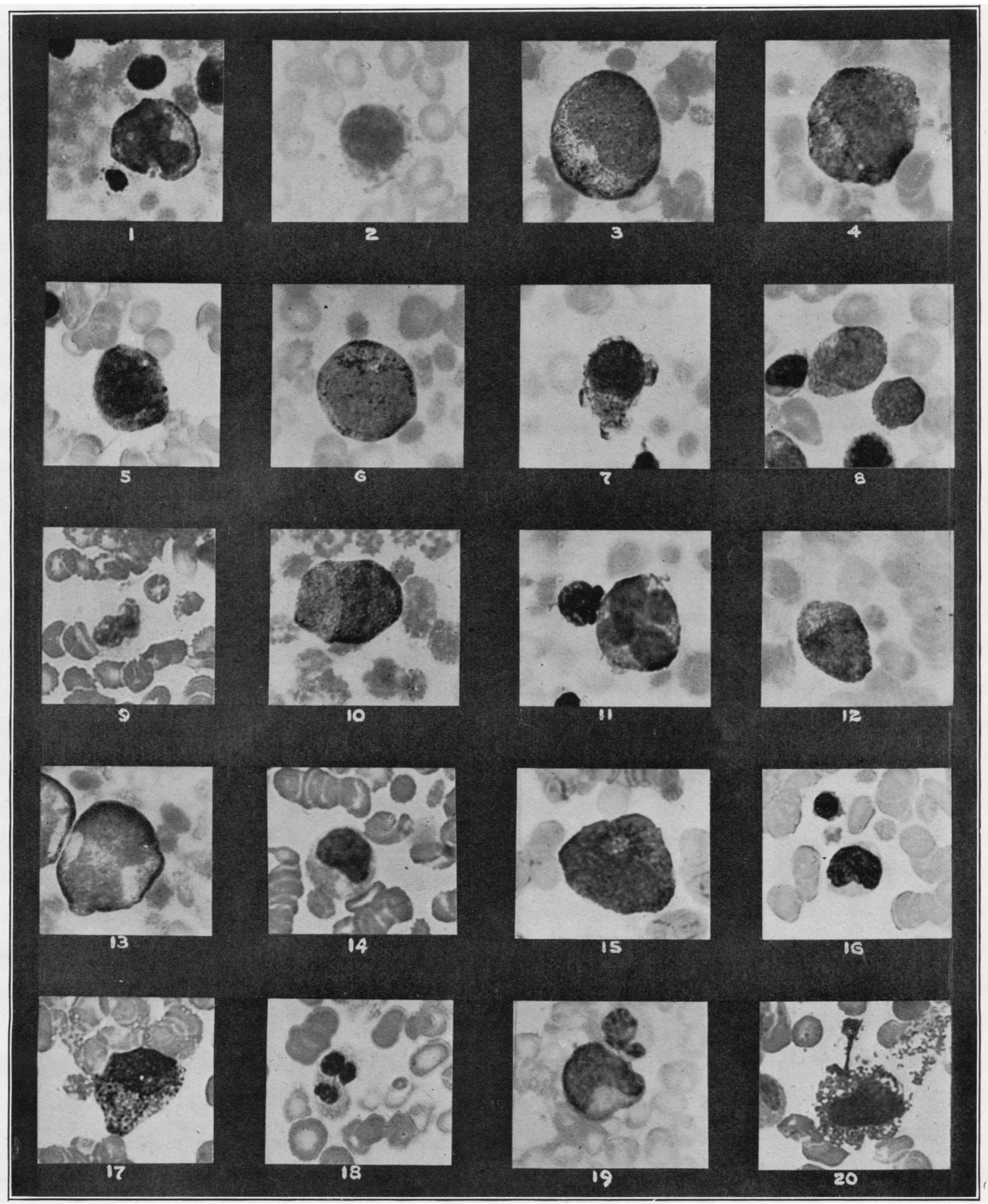

